\title{
Turkish Women's Self-Reported Knowledge and Behavior towards Oral Health during Pregnancy
}

\author{
Buğra Özen ${ }^{a}$ Levent Özer ${ }^{b}$ Feridun Başak ${ }^{c}$ Ceyhan Altun ${ }^{c}$ Cengizhan Açıkel ${ }^{d}$ \\ a Pediatric Dentistry Clinics, Tepebaşı Oral Health Hospital, Ministry of Health of Turkey, ${ }^{\mathrm{b}}$ Department of Pediatric \\ Dentistry, Faculty of Dentistry, Ankara University, and Departments of ${ }^{\mathrm{C} P e d i a t r i c}$ Dentistry and ${ }^{\mathrm{d}}$ Public Health, \\ Gülhane Medical Academy, Ankara, Turkey
}

\section{Key Words}

Pregnancy $\cdot$ Oral health $\cdot$ Oral hygiene

\begin{abstract}
Objectives: The purpose of this study was to evaluate oral health care knowledge and behavior of women during pregnancy. Subjects and Methods: The study population consisted of 351 mothers with children under 3 months of age who presented at Gülhane Medical Academy's Department of Pediatrics for a routine child check-up. Mothers were asked to complete a questionnaire about their knowledge and behavior regarding dental care during pregnancy. $\boldsymbol{R e}$ sults: All the women who participated in the study had dental insurance, and most of them had high levels of education. Of the 351 mothers, 263 (75\%) had heard about possible connections between oral health and pregnancy outcome, and 165 (47\%) believed tooth and periodontal problems could affect pregnancy outcome. However, 256 (73\%) women still believed that calcium would be drawn out of their teeth by the developing baby, and 151 (43\%) believed in the erroneous statement 'A tooth for a baby'. 241 (68.7\%) women had experienced oral health problems during pregnancy; however, only 48 (13.7\%) visited a dentist during their pregnancy. Conclusions: Turkish women, despite having knowledge
\end{abstract}

that adverse pregnancy events may be related to dental and periodontal problems, did not seek oral health care during pregnancy. This suggests the need to better educate medical providers to inform pregnant women to obtain oral health care during pregnancy. Copyright $\odot 2011$ S. Karger AG, Basel

\section{Introduction}

Women need to be aware of the importance of oral health care during and after pregnancy for themselves as well as their children [1]. Early education programs aimed at pregnant women can help to prevent oral diseases in both mother and infant. Dental professionals can play an important role in assuring the well-being of women during their pregnancies by promoting and maintaining their oral health [2].

Pregnancy can increase the incidence and severity of oral disease in women [3]. Pregnant women have been shown to have a higher incidence of gingival inflammation than non-pregnant women [4]. The high estrogen levels in pregnant women can lead to periodontal inflammation, edema, high sensitivity and a tendency to bleed easily, and can cause pre-existing gingivitis to worsen

\section{KARGER \\ Fax +4161306 1234 \\ E-Mail karger@karger.ch}

www.karger.com
(C) 2011 S. Karger AG, Basel

1011-7571/12/0214-0318\$38.00/0

Accessible online at:

www.karger.com/mpp
Buğra Özen

Tepebaşı Agiz ve Dis Sagligi Hastanesi

TR-06280 Keciören, Ankara (Turkey)

Tel. +903123600007

E-Mail bugra_dt@yahoo.com 
Table 1. Demographic characteristics and oral hygiene habits of the 351 participants

\begin{tabular}{llrr}
\hline Characteristic & Category & $\mathrm{n}$ & $\%$ \\
\hline Age group & $\leq 24$ years & 130 & 37 \\
& 25-29 years & 172 & 49 \\
& $\geq 30$ years & 49 & 14 \\
\hline Level of education & primary school & 2 & 0.6 \\
& middle school & 10 & 2.8 \\
& high school & 168 & 47.9 \\
& university & 171 & 48.7 \\
\hline Toothbrushing & less than once a day & 24 & 7 \\
& once a day & 126 & 36 \\
& more than once a day & 201 & 57 \\
\hline $\begin{array}{l}\text { Daily use of inter-proximal } \\
\text { cleaning aids (dental floss) }\end{array}$ & yes & 28 & 8 \\
\hline $\begin{array}{l}\text { Use of oral rinse products at } \\
\text { least once a week }\end{array}$ & yes & 323 & 92 \\
\hline
\end{tabular}

considerably if plaque is not removed [5]. The incidence of gingival inflammation in pregnant women has been reported to range from 30 to $100 \%$ [5-7]. Many studies have shown periodontal disease to be an independent risk factor for pre-term birth and low birth weight [8-11]. In spite of this, factors such as lack of insurance coverage, unfounded beliefs regarding dental treatment during pregnancy and the attitudes of medical as well as dental health providers can limit women's access to dental care during pregnancy [12].

To our knowledge very few Turkish studies $[13,14]$ addressing the extent of mothers' knowledge regarding the associations between oral health and pregnancy outcome have been published. Therefore, the aim of the study was to evaluate Turkish women's knowledge and behavior towards oral health during pregnancy.

\section{Subjects and Methods}

Participants in the present study were chosen from the women with children who presented at Gülhane Medical Academy's Department of Pediatrics for a routine child check-up visit. The inclusion criteria for the study were all women with children under 3 months of age. Written informed consent was obtained from all study participants. The study was approved by the Academy Ethics Committee. A total of 380 women fit the inclusion criteria, and of these 351 women agreed to answer a questionnaire during faceto-face interviews conducted in the Department of Pediatrics waiting room. All interviews with women were carried out by the same dentists (B. Özen, C. Altun).

All of the women had dental insurance, and most (302) were under 30 years of age. The questionnaire was adapted from Habashneh et al. [1] and was designed to assess sociodemographic factors (age, mothers' level of education), oral health habits (dental visits during pregnancy, toothbrushing, other oral hygiene aids), the existence of oral health problems during pregnancy, and women's knowledge and behavior regarding oral health during pregnancy.

Data from the completed questionnaires were analyzed using the SPSS Statistical Software Package (v. 11.5, SPSS Inc., Chicago, III., USA). Chi-square tests were used to analyze data, and descriptive frequency tables were created.

\section{Results}

Demographic characteristics and oral hygiene habits of the participants are given in table 1 . Of the 351 mothers, 302 (86\%) were under 30 years of age (mean $25.79 \pm$ $4.55)$, and all of them were married. All of the study participants had dental insurance. 339 (96.6\%) of them had high levels of education and only 12 women (3.4\%) had graduated from primary and middle schools.

More than half of the women $(201 ; 57 \%)$ brushed their teeth more than once a day and almost all $(327 ; 93 \%)$ brushed at least once a day, whereas 28 (8\%) participants used dental floss or 11 (3\%) used mouth rinse. Participants with higher levels of education brushed more frequently than less educated participants, but the difference was not statistically significant ( $p>0.05)$.

Information pertaining to oral health problems and dental care is given in table 2. 241 (68.7\%) women experienced oral health problems during pregnancy. The difference in the proportion of women who had regular dental check-ups before pregnancy $(135 ; 38.5 \%)$ and during pregnancy $(48 ; 13.7 \%)$ was statistically significant ( $\mathrm{p}<$ 0.01 ). Among the 303 women who did not visit a dentist during their pregnancy, 201 (57.2\%) stated that they thought the dentist would use local anesthetics or prescribe antibiotics without consulting their medical doctor and/or could not perform any type of treatment during their pregnancy.

Mothers' knowledge about possible associations between pregnancy outcome and oral health is given in table 3. 151 of the participants (43\%) believed in the truth of the saying 'A tooth for a baby', and the majority, 256 (73\%) women, believed that calcium would be drawn out of their teeth by the developing fetus. Nearly half of the participants, 165 (47\%), thought that tooth and periodontal problems could affect pregnancy outcome. 263 (75\%) 
Table 2. Oral health problems and dental care of participants during pregnancy

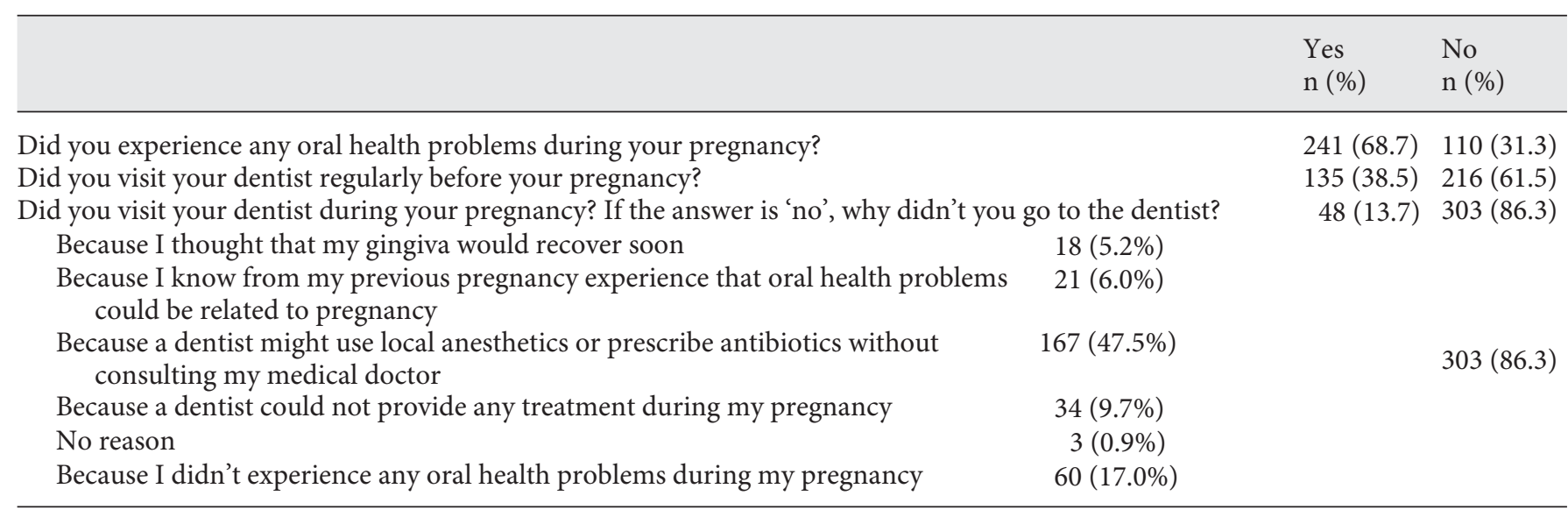

Table 3. Participants' knowledge regarding associations between pregnancy outcome and oral health (as reflected in responses to knowledge statements)

\begin{tabular}{|c|c|c|c|}
\hline \multicolumn{2}{|l|}{ Knowledge statement } & $\begin{array}{l}\text { Yes } \\
\text { n (\%) }\end{array}$ & $\begin{array}{l}\text { No } \\
\text { n (\%) }\end{array}$ \\
\hline \multicolumn{2}{|c|}{ Do you believe in the truth of the saying 'A tooth for a baby'? } & $151(43.0)$ & $200(57.0)$ \\
\hline \multicolumn{2}{|c|}{ Do you believe calcium will be drawn out of your teeth by the developing fetus? } & $256(73.0)$ & $95(27.0)$ \\
\hline \multicolumn{2}{|c|}{ Do you believe periodontal problems can affect pregnancy outcome? } & $165(47.0)$ & $186(53.0)$ \\
\hline \multicolumn{2}{|c|}{$\begin{array}{l}\text { Have you heard about a possible connection between oral health and pregnancy? If the answer is 'yes', } \\
\text { where did you hear this? }\end{array}$} & $263(75.0)$ & $88(25.0)$ \\
\hline I read it in a book, magazine or the internet & $77(21.9)$ & & \\
\hline My medical doctor told me about it & $75(21.4)$ & & \\
\hline My dentist told me about it & $45(12.8)$ & & \\
\hline I heard it from people around me & $41(11.7)$ & $263(75.0)$ & \\
\hline From my previous experience with pregnancy & $18(5.2)$ & & \\
\hline Other & $7(2.0)$ & & \\
\hline \multicolumn{2}{|c|}{ Did you receive any instructions on oral health care from your health care provider during your pregnancy? } & $109(31.0)$ & $242(69.0)$ \\
\hline
\end{tabular}

women reported having heard about a possible connection between pregnancy and oral health, but only 109 (31\%) women had received any instructions regarding oral health care from their medical health care providers.

\section{Discussion}

This study has shown an important but often neglected aspect of antenatal care that plays a crucial role in the overall health of pregnant women and their newborn children. Many women do not seek dental care during their pregnancy, and those who do often confront unwillingness by dentists to provide care $[12,15,16]$. Women who neglected to visit a dentist to receive proper dental care while pregnant were reported to have problems during their pregnancy $[12,17]$. Several previous reports found having dental insurance to be strongly associated with a dental visit during pregnancy $[1,3,12,18,19]$. Even in countries where pregnant women have access to free public dental services, such as Greece and the UK, the utilization of dental services is very low $[15,20,21]$. Similarly, in spite of the fact that all of the participants in the present study had dental insurance, only $13.7 \%$ of pregnant women visited a dentist during pregnancy. The attitudes and beliefs of care providers, including physicians, may also limit access to dental care during pregnancy. According to the results of a survey on obstetricians 
[22], a majority of participants believed that consultations with a dentist before dental treatment were unnecessary. In the same study, $60 \%$ of the participants thought that dentists were too cautious in their care of pregnant patients, and only a minor group of obstetricians was concerned that dentists might prescribe antibiotics without a consultation. While this study did not aim to assess the attitudes of physicians toward dental care during pregnancy, it could be speculated that their potential lack of attention to the dental profession or oral health may adversely affect the overall awareness of their patients. According to the American Academy of Pediatric Dentistry's Guideline on Perinatal Oral Health Care [16], the most important message for pregnant women and health care professionals is that dental care is safe and effective during pregnancy. Presumably, the most striking finding of the present study was that $57.2 \%$ of the participants did not visit a dentist during pregnancy because they feared being given local anesthetics or prescribed antibiotics without consulting a physician and/or because they did not think that any dental treatment could be performed during pregnancy. This finding is confirmed by previous studies [12, 23].

The present findings confirmed a previous survey [1] showing that almost half of the participants were aware of a possible connection between oral health and pregnancy outcome. Despite such awareness only a minority of pregnant women in this study visited a dentist during their pregnancy. This finding may indicate that awareness of the relationship between dental health and preg- nancy outcome may not necessarily lead to appreciation of its significance by an individual. Thus, health professionals should aim to encourage pregnant patients to seek regular dental care until birth [23-25]. Previous studies [26-28] have shown periodontal disease to be a significant risk factor for pregnancy outcomes such as pre-term low birth weight. In the present study, mothers were not certain about this relationship, thereby indicating that pregnant women require education on oral health maintenance and the link between oral health of the mother and overall health of the newborn $[2,8]$. We therefore suggest that a multidisciplinary medical team including dentists should assume a more active role in providing oral health education to pregnant women.

\section{Conclusion}

In spite of the fact that a large proportion of the Turkish women in this study reported having oral health problems during pregnancy, most of them did not visit a dentist during their pregnancy, and two thirds did not receive oral health care instructions from their medical provider. Therefore, women need to be better educated regarding dental health during pregnancy.

\section{Disclosure Statement}

The authors declare that they have no competing interests.

\section{References}

1 Habashneh R, Guthmiller JM, Levy S, Johnson GK, Squier C, Dawson DV, Fang Q: Factors related to utilization of dental services during pregnancy. J Clin Periodontol 2005; 32:815-821.

-2 Katz J, Orchard AB, Ortega J, Lamont RJ, Bimstein E: Oral health and preterm delivery education: a new role for the pediatric dentist. Pediatr Dent 2006;28:494-498.

-3 Watson MR, Gibson G, Guo I: Women's oral health awareness and care-seeking characteristics: a pilot study. J Am Dent Assoc 1998; 129:1708-1716.

-4 Nuamah I, Annan BD: Periodontal status and oral hygiene practices of pregnant and non-pregnant women. East Afr Med J 1998; 75:712-714.

5 Ferris GM: Alteration in female sex hormones: their effect on oral tissues and dental treatment. Compendium 1993;14:1558-1571.
-6 Zachariasen RD: Pregnancy gingivitis. J Gt Houst Dent Soc 1997;69:10-12.

7 Christensen LB, Jeppe-Jensen D, Petersen PE: Self-reported gingival conditions and self-care in the oral health of Danish women during pregnancy. J Clin Periodontol 2003; 30:949-953.

-8 Jeffcoat MK, Geurs NC, Reddy MS, Cliver SP, Golden-Berg RL, Hauth JC: Periodontal infection and preterm birth. Results of a prospective study. J Am Dent Assoc 2001;132: $875-880$

$\checkmark$ Dasanayake A: Poor periodontal health of the pregnant woman as a risk factor for low birth weight. Ann Periodontol 1998;3:206212.
10 Offenbacher S, Leiff S, Boggess KA, Murtha AP, Madianos PN, Champagne CM, McKaig RG, Jared HL, Mauriello SM, Auten RL Jr, Herbert WN, Beck JD: Maternal periodontitis and prematurity. Part I: Obstetric outcome of prematurity and growth restriction. Ann Periodontol 2001;6:164-174.

11 Lopez N, Smith P, Gutierrez J: Periodontal therapy may reduce the risk of preterm low birthweight in women with periodontal disease. J Periodontol 2002;73:911-924.

12 Gaffield ML, Gilbert BJ, Malvitz DM, Romaguera R: Oral health during pregnancy. An analysis of information collected by the Pregnancy Risk Assessment Monitoring System. J Am Dent Assoc 2001;132:1009-1016.

13 Buduneli N, Baylas H, Buduneli E, Türkoğlu O, Köse T, Dahlaen G: Periodontal infections and preterm low birth weight: a case-control study. J Clin Periodontol 2005;32:174-181. 
14 Toygar HU, Sevdaoglu G, Kurklu S, Guzeldemir E, Arpak N: Periodontal health and adverse pregnancy outcome in 3,576 Turkish women. J Periodontol 2007;78:2081-2094.

15 Keirse MJ, Plutzer K: Women's attitudes to and perceptions of oral health and dental care during pregnancy. J Perinat Med 2010; 38:3-8.

$16 \mathrm{http} / / / \mathrm{www}$.aapd.org/media/Policies Guidelines/G_PerinatalOralHealthCare. pdf (accessed August 10, 2011).

17 George A, Johnson M, Blinkhorn A, Ellis S, Bhole S, Ajwani S: Promoting oral health during pregnancy: current evidence and implications for Australian midwives. J Clin Nurs 2010;19:3324-3333.

18 Mangskau KA, Arrindell B: Pregnancy and oral health: utilization of the oral health care system by pregnant women in North Dakota. Northwest Dent 1996;75:23-28.

19 Lydon-Rochelle M, Krakowiak P, Hujoel PP, Peters RM: Dental care use and self-reported dental problems in relation to pregnancy. Am J Public Health 2004;94:765-771.
20 Dinas K, Achyropoulos V, Hatzipantells E, Marromatida G, Zepiridis L, Theodoridis T, Dovas D, Tantanasis T, Goutzioulis F, Bontis J: Pregnancy and oral health: utilisation of dental services during pregnancy in northern Greece. Acta Obstet Gynecol Scand 2007; 86:938-944.

21 Hullah E, Turo Y, Nauta M, Yoong W: Selfreported oral hygiene habits, dental attendance and attitudes to dentistry during pregnancy in a sample of immigrant women in North London. Arch Gynecol Obstet 2008; 277:405-409.

22 Shrout MK, Comer RW, Powell BJ, McCoy HP: Treating the pregnant dental patient: four basic rules addressed. J Am Dent Assoc 1992;123:75-80.

23 Rogers SN: Dental attendance in a sample of pregnant women in Birmingham, UK. Community Dent Health 1991;8:361-368.

24 Honkala S, Al-Ansari J: Self-reported oral health, oral hygiene habits, and dental attendance of pregnant women in Kuwait. J Clin Periodontol 2005;32:809-814.
25 Gunay H, Goepel K, Stock KH, Schneller T: Position of health education knowledge concerning pregnancy (in German). Oralprophylaxe 1991;13:4-7.

26 Offenbacher S, Katz V, Fertik G, Collins J, Boyd D, Maynor G, McKaig R, Beck J: Periodontal infection as a possible risk factor for preterm low birth weight. J Periodontol 1996; 67:1103-1113.

-27 Saddki N, Backok N, Hussain NHN, Zainudin STA, Sosroseno W: The association between maternal periodontitis and low birth weight infants among Malay women. Community Dent Oral Epidemiol 2008;36:296304.

28 Cruz SS, Costa MdaCN, Gomes-Filho IS, Rezende EJC, Barreto ML, dos Santos CAST, Vianna MIP, Passos JS, Cerqueira EMM: Contribution of periodontal disease in pregnant women as a risk factor for low birth weight. Community Dent Oral Epidemiol 2009;37:527-533. 